See discussions, stats, and author profiles for this publication at: https://www.researchgate.net/publication/279808064

\title{
The "Heart"-Shaped Flap for Soft-Tissue Reconstruction in Complex Avulsion Injury of the Hand
}

Article in Plastic and Reconstructive Surgery · June 2015

DOI: $10.1097 /$ PRS. 0000000000001606 · Source: PubMed

CITATIONS

4 authors:

Sergio Razzano

Norfolk and Norwich University Hospitals NHS Foundation Trust

27 PUBLICATIONS 38 CITATIONS

SEE PROFILE

Richard Haywood

Norfolk and Norwich University Hospitals NHS Foundation Trust

43 PUBLICATIONS 191 CITATIONS

SEE PROFILE
READS

80

Nicholas Sheppard

Norfolk and Norwich University Hospitals NHS Foundation Trust

2 PUBLICATIONS OCITATIONS

SEE PROFILE

Samuel Norton

Norfolk and Norwich University Hospitals NHS Foundation Trust

3 PUBLICATIONS 7 CITATIONS

SEE PROFILE 


\section{Plastic and Reconstructive Surgery Advance Online Article}

\section{DOI: 10.1097/PRS.0000000000001606}

The "heart" shaped flap for soft tissue reconstruction in complex avulsion injury of the hand.

Sergio Razzano

Nicholas Sheppard (corresponding author)

Richard Haywood

Samuel Norton

All care of:

Department of Plastic Surgery

Norfolk and Norwich University Hospital

Colney Lane

Norwich

NR4 7UY

Tel: 01603286286

None of the authors has a financial interest in any of the products, devices, or drugs mentioned in this manuscript.

No acknowledgements. 


\section{The "heart" shaped flap for soft tissue reconstruction in complex avulsion injury of the hand.}

\section{Sir:}

We have read the article by Terence L. H. et al with interest [1].The authors pointed out the benefits of the superficial circumflex iliac artery (SCIA) perforator flap as a thin skin flap, very useful for single-stage reconstruction of cutaneous defects. Their modifications to the original technique [2] extended the possibilities for its application. In our experience there are situations where a larger flap is needed that require bulk in the central part whilst a thinner flap is preferred at the periphery. We recently treated a case with both of these needs, using a free bilobed "heart shaped" superficial circumflex iliac artery flap allowing fish-mouth closure [3] for the coverage of a multi digit defect.

A 26yo abattoir worker caught his non-dominant left hand in a meat-processing machine sustaining an avulsion of the index, middle and ring fingers with a boney level at the proximal interphalangeal joints and a soft-tissue level below the metacarpophalangeal joints. The long flexors were avulsed from the muscular insertions, but extensor mechanisms and intrinsic function were preserved. The amputate was not salvageable, having subsequently dropped into a vat of hot water as part of the machine's process. A bilobed free groin flap was employed in order to provide adequate volar and dorsal padding while being thin enough to retain function, particularly where inset into the webspaces. Fig 1.

We utilized the supra-Scarpa plane dissection laterally while harvesting the flap on the main superficial circumflex iliac artery (SCIA) vessel without isolating the perforator [4] for several reasons: firstly we wanted to increase the reliability of the flap. The complex nature of our defect required a tailored, large skin paddle so the decision was made to add a venous supercharge by including the superficial inferior epigastric vein. Secondly, by raising the flap in 
a deeper plane centrally, the bulk of the flap provides padding on the radial aspect of the first metacarpal and the volar surface. The authors outlined disadvantages of their technique in terms of vessel calibre and flap size. We feel that if there is need is to have a larger flap, it is safer to raise it on the main vessel, but peripheral supra-Scarpa's dissection, as they described, can still provide a flap with a thin component [5]. This approach is particularly useful for defects that are deeper centrally than in the periphery, and also when there is the need to have bulk in part for padding, while the remainder needs thin, pliable tissue. Thirdly, the bilobed "heart" shaped tailoring allowed us to perform a fish mouth closure and contour the flap to the defect (Fig 2). Lastly, it also allowed a T shaped donor site closure, avoiding a longer longitudinal scar to correct possible dog ears. We have found this flap suitable for large, three-dimensional defects requiring different thickness in the same flap.

\section{References}

1. Goh TL, Park SW, Cho JY, Choi JW, Hong JP. The search for the ideal thin skin flap: superficial circumflex iliac artery perforator flap-a review of 210 cases. Plast Reconstr Surg. 2015 Feb;135(2):592-601.

2. Koshima I, Nanba Y, Tsutsui T, et al. Superficial circumflex iliac artery perforator flap for reconstruction of limb defects. Plast Reconstr Surg. 2004;113:233-240.

3. Ellabban MG, Bremner N.'Fish mouth' modification for enhancing the advancement of V-Y flap. J Plast Reconstr Aesthet Surg. 2007;60(2):213-5. Epub 2006 Nov 22.

4. McGregor IA, Jackson IT. The groin flap. Br J Plast Surg. 1972 Jan;25(1):3-16.

5. Hong JP, Choi DH, Suh H, Mukarramah DA, Tashti T, Lee K, Yoon C. A new plane of elevation: the su perficial fascial plane for perforator flap elevation. J Reconstr Microsurg. 2014 Sep;30(7):491-6.

Figure Legend:

Figure 1. Flap raised in "Heart" shape as a bilobed groin flap. Black arrow: main pedicle ( SCIA and SCIV). White arrow : Superficial inferior epigastric vein (SIEV).

Figure 2. Volar view of the flap inset. 
Figure 1.
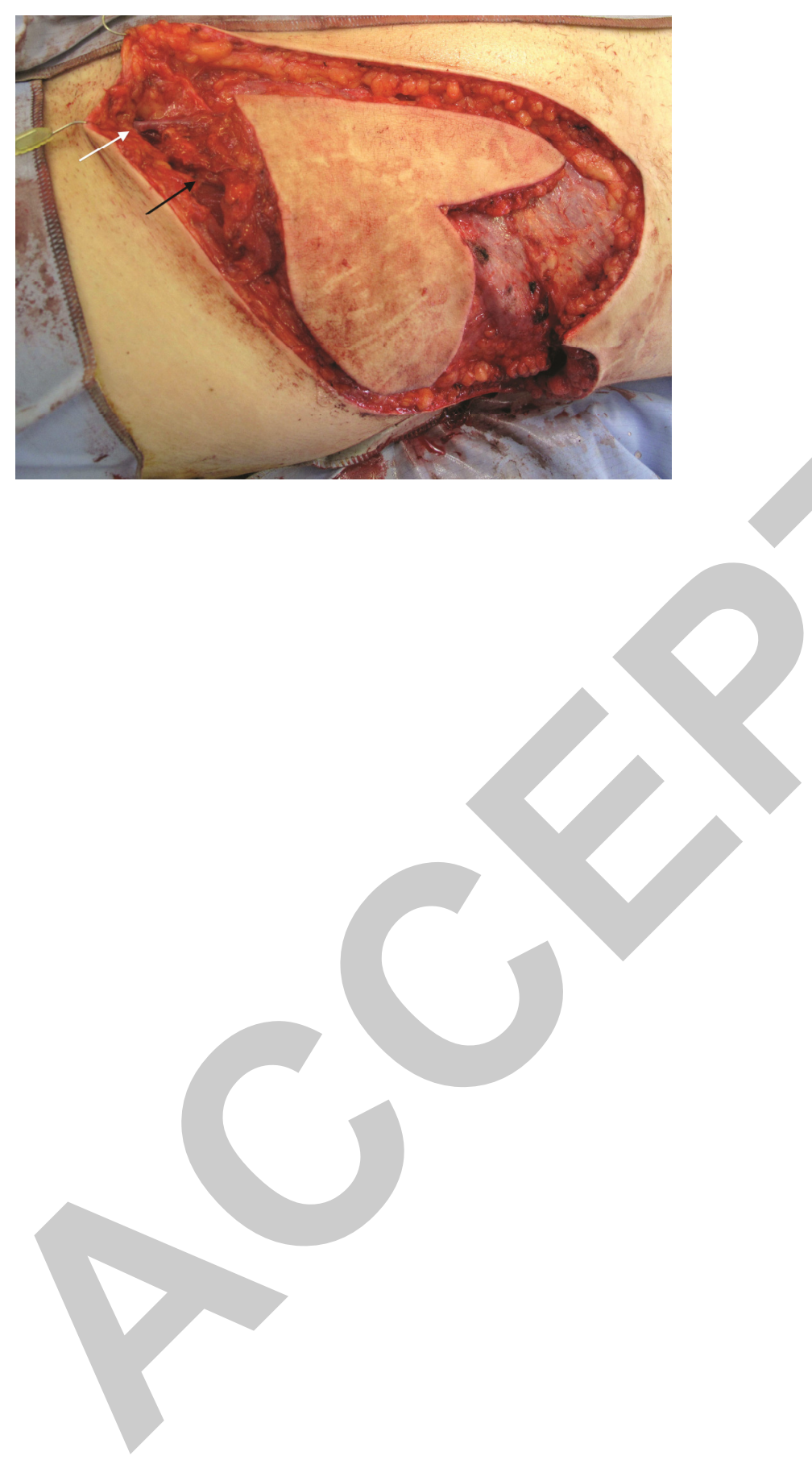

Copyright (c) American Society of Plastic Surgeons. All rights reserved. 
Figure 2.
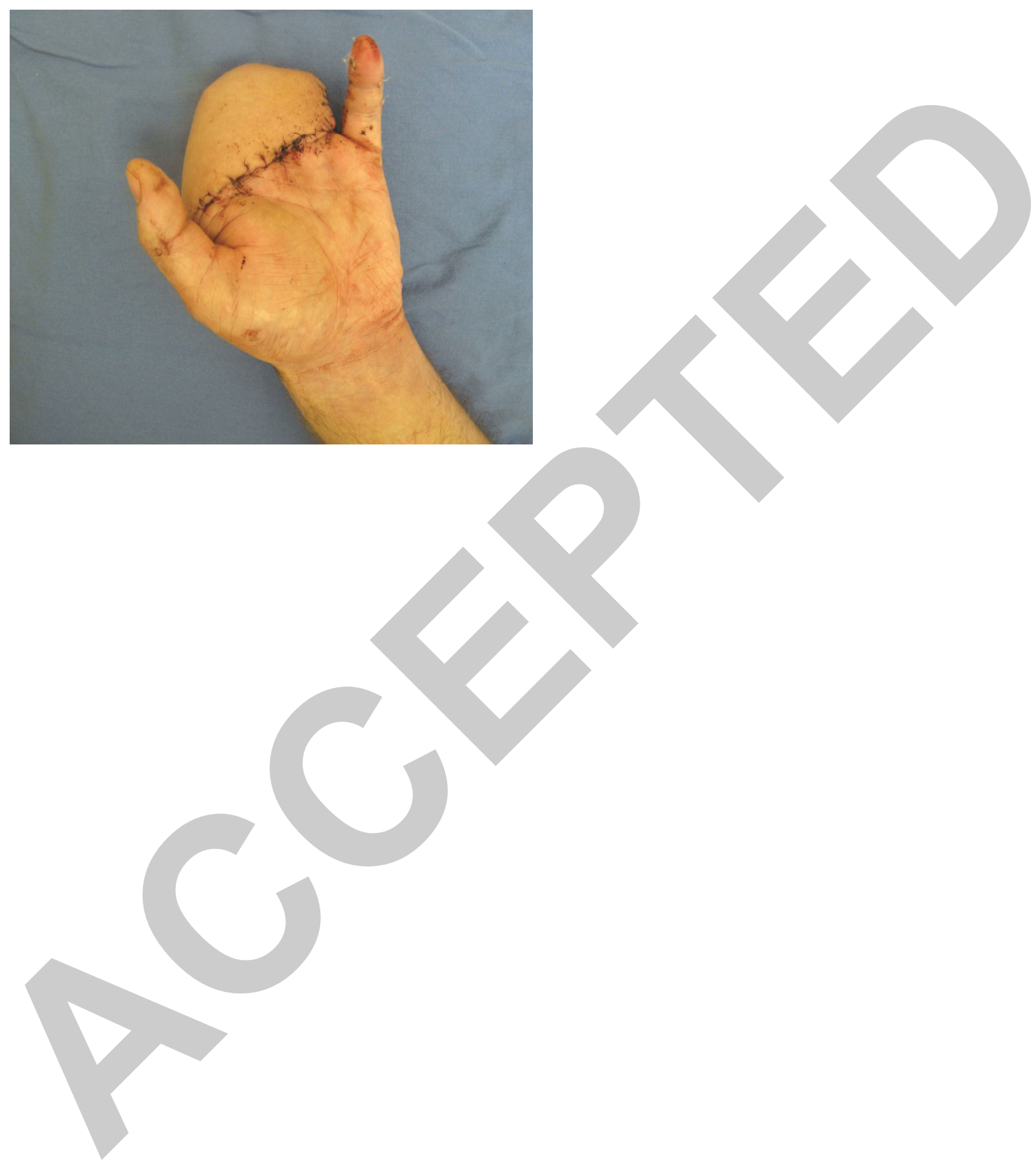

Copyuright (c) American Society of Plastic Surgeons. All rights reserved. 